\title{
Work Related Complaints among Dentists
}

\author{
Shrestha BP, ' Singh GK, ${ }^{1}$ Niraula SR ${ }^{2}$ \\ 'Department of Orthopaedics; ${ }^{2}$ Department of Community Medicine, B.P. Koirala Institute of Health Science, Dharan, Nepal
}

\begin{abstract}
The objective of this study was to describe the occurrence of neck pain, shoulder pain and back pain among dentists and to assess the risk factors affecting them.

Sixty-eight dentists from Dharan and Biratnagar were interviewed using pretested questionnaires in January 2006. Back pain was the most common complaint affecting almost $80 \%$ of the study population, followed by neck pain $(58.8 \%)$ and shoulder pain $(47 \%)$. The frequency of shoulder pain among female dentists was nearly double that of males $(\mathrm{P}=0.009)$. The mean days of neck pain among males was significantly higher as compared to females $(\mathrm{P}=0.048)$. The study suggests that musculoskeletal complaints are common among dentists, though they are not of severe nature. There is a scope for further decreasing the prevalence and severity of these disorders by performing regular specific exercises.
\end{abstract}

Key words: back pain, dentists, neck pain, shoulder pain

\section{INTRODUCTION}

Dentistry is a demanding profession regarding concentration and precision. Most dentists today work in the sitting position treating the patient in the supine position. Because their work area (the mouth of the patient) is narrow, performance of dental treatment results in a very inflexible work posture. ${ }^{1}$ Studies have shown that dentists have a high frequency of musculoskeletal disorders. ${ }^{2-4}$

There are large numbers of studies relating to musculoskeletal complaints among dental surgeons in the Western literature but none has been conducted in Nepal. This study has been conducted to assess the work-related complaints among dentists in our region with the specific objectives to find out the prevalence of neck, shoulder and back pain among the dental surgeons and to identify the risk factors associated with these symptoms.

\section{MATERIAL AND METHODS}

This is a cross-sectional study conducted in 68 dental surgeons who were interviewed using pretested questionnaires in January 2006. Sixty-three were from the College of Dental Surgery, B.P. Koirala Institute of Health Sciences, Dharan, and five were private practitioners from Dharan and Biratnagar. Any dental surgeon who had passed the Bachelor of Dental Surgery (BDS) and working was considered eligible for the study and so all dental surgeons available in Dharan and Biratnagar filled the pro-formas voluntarily. BDS students were not included in the study. The instrument consisted of various questions about gender, type of dentistry, frequent breaks, right posture, neck pain, shoulder pain, back pain, analgesic-use and exercise.

\footnotetext{
Correspondence:

Dr. Bikram Prasad Shrestha

Department of Orthopaedics

B.P. Koirala Institute of Health Sciences Dharan, Nepal

Email: bikramshrestha@yahoo.com
} 
Shrestha et al. Work Related Complaints among Dentists

The study was approved by the Ethical Review Board of the Research Committee of B.P. Koirala Institute of Health Sciences, one of the authorized institutions of the Nepal Health Research Council. Before the data collection, written permission and verbal consent from each respondent were obtained. The study was conducted without any support of funds from anywhere.

Data were entered into the Microsoft excel program and analyzed using SPSS (Statistical Package for Social Sciences) version 12.0 software. The collected data was summarized by calculating frequency and percentage for discrete variables and mean, standard deviation for continuous variables like working days lost due to back pain, shoulder pain and neck pain. The analysis was performed by using $\chi^{2}$ test to identify the significant difference between the discrete data. MannWhitney $U$ test, a non parametric test, was applied to test the significance of difference amongst continuous variables. Alpha $(\alpha)$ value was set at 0.05 .

\section{RESULTS}

Among the dental surgeons interviewed, 39 (57\%) were males (mean age 29.56 years) and 29 (43\%) were females (mean age 24.93). Eighteen dentists (26.5\%) practised sitting and $50(73.5 \%)$ dentists practiced sitting and standing dentistry. Fifty eight (85.3\%) respondents said they had frequent breaks during work whereas $10(14.7 \%)$ said they did not.

Forty percent (27) of the dental surgeons considered endodontic procedures to be the most tiring dental procedure. The second and third most tiring dental procedures (20\% each) were impacted teeth extraction and dental fabrication procedures.

Fifty dentists $(73.5 \%)$ thought they practiced the right posture and $18(26.5 \%)$ thought they did not. Fifty $(73.5 \%)$ felt that their musculoskeletal complaints were significantly contributed to by their dental work.

Fifty-four dentists (79.4\%) had at least one episode of backache in the last one year. Among them 38 (55.9\%) had mild pain, $13(19.4 \%)$ had moderate pain and only $2(3 \%)$ had severe pain. Forty $(58.8 \%)$ dentists had at least one episode of neck pain during the last one year. Twenty-nine $(42.6 \%)$ had mild pain, $8(11.8 \%)$ had moderate and $4(5.9 \%)$ had severe pain.

Shoulder pain was less common. Only 32 (47.1\%) had at least one episode of shoulder pain in the last one year. Among those who had shoulder pain, 27 (39.7\%) had mild pain, $4(5.9 \%)$ had moderate and $4(6 \%)$ had severe pain.

Out of the 54 dentists who had back pain, only nine $(16.7 \%)$ sought medical treatment. Only five dentists
(7.4\%) sought treatment for shoulder and neck pain. The reason for not seeking medical treatment for shoulder and neck pain was stated by $38(55.9 \%)$ as the pain being mild and self-limiting and by $7(10.3 \%)$ that they resorted to self-medication.

Twenty-five dentists (36.8\%) said that they take self medication for their musculoskeletal complaints. Thirty three $(48.5 \%)$ did not take medicines on their own. Ten $(14.7 \%)$ did not respond to the questions. The mean number of days of back pain, shoulder pain and neck pain are shown in Table 1. The mean working days lost due to back pain (Table 4).

The analgesics that were taken included Diclofenac sodium, Ibuprofen, Nimesulide, combination of Paracetamol and Ibuprofen, and some others. Of all these, Nimesulide was the most commonly preferred analgesics, being used by $14.7 \%$, followed closely by Diclofenac sodium (13.2\%).

Regarding exercise for backache, 21 (30.9\%) said they exercised regularly. Thirty-five $(51.5 \%)$ did not exercise and $12(17.6 \%)$ did not respond. Of the 21 who exercised, 13 said they learnt the exercises themselves. Seven were taught by orthopaedic surgeons. One did not respond. Only 12 dental surgeons (17.6\%) did regular exercise for the prevention or treatment of neck pain. Out of this, eight had had learnt the exercises themselves and four had been taught by orthopaedic surgeons.

Twenty-four (35.3\%) of the dental surgeons attributed their shoulder and neck pain to endodontic procedures.

Sixty-nine percent of females had neck pain whereas only $51 \%$ of males had it. $\left(\chi^{2}=2.15\right.$, df $\left.=1, P=0.143\right)$. The frequency of shoulder pain among the females was nearly double than that of males. $\left(\chi^{2}=6.9, \mathrm{df}\right.$ $=1, P=0.009)$. The probability of significance shows that gender did not have significant relation with the frequency of back pain (Table 1-3).

It was observed that the type of dentistry did not affect the frequency of neck pain, shoulder pain or back pain significantly. The data also suggests that frequent breaks during work did not influence frequency of neck pain $\left(\chi^{2}=0.38, \mathrm{df}=1, \mathrm{P}=0.54\right)$ or the shoulder pain $\left(\chi^{2}=0.79, \mathrm{df}=1, \mathrm{P}=0.37\right)$. Frequency of breaks did not have significant relation with the frequency of back pain as well.

The interviewees were asked whether they thought they practised right the posture or not. There was no significant difference in the frequency of neck, shoulder and back pain between those who thought they practised right posture and those who did not (Table 2-4). 
Shrestha et al. Work Related Complaints among Dentists

There was no significant difference in the working days lost and the number of days of back pain, shoulder pain and neck pain between the males and females $(P>0.05)$ (Table 4).

Questions were asked to find out whether the males or females tended to take frequent breaks. No significant difference was noted between the two $\left(\chi^{2}=0.77\right.$, $\mathrm{df}=1, \mathrm{P}=0.38$ ).

\section{DISCUSSION}

This study shows the high prevalence of musculoskeletal complaints among the dental surgeons, back pain being the most common, followed by neck pain and shoulder pain. In a study conducted by Alexopoulos et al, they observed similar results. ${ }^{5}$ Szymananska in his study reported that symptoms connected to the back were the most common. ${ }^{6}$ Most studies consistently report that back pain is the most common musculoskeletal complaint among the dental surgeons.

In our study the mean working days lost due to back pain was 0.64 , with standard deviation 1.73 . Only $3 \%$ had severe back pain. Only $16 \%$ of those suffering back pain sought medical treatment. This suggests that back pain among dental surgeons is not of a severe nature. Al Wazzan et al in their study noted that only $37 \%$ of those suffering from back pain and neck pain sought medical treatment and concluded that these symptoms among dental personnel are not of severe nature. ${ }^{7}$

This study shows that the majority of the dental surgeons did not perform specific exercises to prevent or lessen back, neck and shoulder pain.

We observed that the frequency of shoulder pain among the females was nearly double than that of males, which is significant. Gender however did not have any relation with back and neck pain. Rundcrantz et al in their prospective study interviewed 311 dentists in 1987 and also in 1990. As in 1987, female dentists had also in 1990 a higher prevalence of pain and discomfort in the neck and shoulder as compared to their male colleagues. ${ }^{8}$

Navah et al conducted a study to determine the effect of work posture on musculoskeletal complaints. They concluded that those working only in the sitting position had a more severe low back pain than those who alternated between the sitting and standing positions. ${ }^{9}$ We are not able to comment on the severity of the symptoms but we found no difference in the prevalence of symptoms among those who practised the sitting type of dentistry and those who practised the sitting and standing type.
We tried to find out the relation of posture to the prevalence of back pain, shoulder pain and neck pain and found that it had no relation with any of them.

This study suggests that taking frequent breaks does not decrease the prevalence of musculoskeletal symptoms. Szymanska tried to find out the relationship between the working time without breaks and the number of episodes experienced, but found no difference in the frequency of symptoms in dentists working with or without breaks. ${ }^{6}$ Marshal et al also did not find any difference in the symptoms in dentists who worked with or without frequent breaks. ${ }^{10}$

We have tried to find the difference in prevalence of musculoskeletal complaints among those who thought they practised the right posture and those who thought they practised the wrong posture. There was no significant difference noted. This would mean that all practised similar posture in spite of what they thought.

Because the musculoskeletal complaints were mostly mild, the mean working days lost was only 0.64 day. Gender did not affect the number of days lost and the number of days of symptoms. EC Alexopoulos has reported in his study that female gender was significantly related to chronic back pain $(O R=2.42 ; 95 \% \mathrm{Cl}=1.22$ 4.82) and chronic shoulder pain $(\mathrm{OR}=4.51 ; 95 \% \mathrm{Cl}$ 1.72-11.85). Both sexes tended to take an equal number of breaks during work. ${ }^{5}$

This study cannot be generalized to the whole of Nepal as the data only represent the dentists working in the eastern part of Nepal. Therefore, this can be considered a limitation of the study.

\section{CONCLUSION}

This study suggests that musculoskeletal complaints are common among dentists. Back pain is the most common complaint followed by neck pain and shoulder pain, though they all are usually mild. There was no significant difference between male and female dentists with regard to musculoskeletal symptoms and most thought they practised the right posture without actually doing so. Most dentists do not perform specific exercises for the prophylaxis of neck, shoulder and back pain. There is a scope for further decreasing the prevalence and severity of these disorders by performing regular specific exercises.

\section{ACKNOWLEDGEMENTS}

The authors are thankful to all the dental surgeons who participated in the study by responding the questionnaires and to the Research Committee of B.P. Koirala Institute of Health Sciences, Dharan. 
Shrestha et al. Work Related Complaints among Dentists

Table 1. Distribution of neck pain in relation to different variables

\begin{tabular}{|c|c|c|c|c|c|}
\hline & & \multicolumn{2}{|c|}{ Neck Pain } & \multirow[t]{2}{*}{$\chi^{2}$ value } & \multirow[t]{2}{*}{$P$ value } \\
\hline & & Yes & No & & \\
\hline \multirow[t]{2}{*}{ Gender } & Male (39) & $20(51.3 \%)$ & $19(48.7 \%)$ & 2.15 & 0.143 \\
\hline & Females (29) & $20(69.0 \%)$ & $9(31.0 \%)$ & & \\
\hline \multirow[t]{2}{*}{ Type of dentistry } & Sitting & $11(61.1 \%)$ & $7(38.9 \%)$ & 0.05 & 0.82 \\
\hline & Sitting and Standing & $29(58.0 \%)$ & $21(42.0 \%)$ & & \\
\hline \multirow[t]{2}{*}{ Frequent breaks } & Yes & $35(60.3 \%)$ & $23(39.7 \%)$ & 0.38 & 0.54 \\
\hline & No & $5(50.0 \%)$ & $5(50.0 \%)$ & & \\
\hline \multirow[t]{2}{*}{ Right posture } & Yes & $28(41.2 \%)$ & $22(44.0 \%)$ & 0.62 & 0.43 \\
\hline & No & $12(66.7 \%)$ & $6(33.3 \%)$ & & \\
\hline
\end{tabular}

Table 2. Distribution of shoulder pain in relation to different variables

\begin{tabular}{|c|c|c|c|c|c|}
\hline & & \multicolumn{2}{|l|}{ Shoulder Pain } & \multirow[t]{2}{*}{$\chi^{2}$ value } & \multirow[t]{2}{*}{$P$ value } \\
\hline & & Yes & No & & \\
\hline \multirow[t]{2}{*}{ Gender } & Male (39) & $13(33.3 \%)$ & $26(66.7 \%)$ & 6.9 & 0.009 \\
\hline & Females (29) & $19(65.5 \%)$ & $10(34.5 \%)$ & & \\
\hline \multirow[t]{2}{*}{ Type of dentistry } & Sitting & $6(33.3 \%)$ & $12(66.7 \%)$ & 0.79 & 0.37 \\
\hline & Sitting and Standing & $26(52.0 \%)$ & $24(48.0 \%)$ & & \\
\hline \multirow[t]{2}{*}{ Frequent breaks } & Yes & $26(44.8 \%)$ & $32(55.2 \%)$ & 0.79 & 0.38 \\
\hline & No & $6(60.0 \%)$ & $4(40.0 \%)$ & & \\
\hline \multirow[t]{2}{*}{ Right posture } & Yes & $20(40.0 \%)$ & $30(60.0 \%)$ & 3.78 & 0.052 \\
\hline & No & $12(66.7 \%)$ & $6(33.3 \%)$ & & \\
\hline
\end{tabular}

Table 3. Distribution of back pain in relation to different variables

\begin{tabular}{|c|c|c|c|c|c|}
\hline & & \multicolumn{2}{|l|}{ Back Pain } & \multirow[t]{2}{*}{$\chi^{2}$ value } & \multirow[t]{2}{*}{$P$ value } \\
\hline & & Yes & No & & \\
\hline \multirow[t]{2}{*}{ Gender } & Male (39) & $29(74.4 \%)$ & $10(25.6 \%)$ & 1.43 & 0.23 \\
\hline & Females (29) & $25(86.2 \%)$ & $4(13.8 \%)$ & & \\
\hline \multirow[t]{2}{*}{ Type of dentistry } & Sitting & $16(88.9 \%)$ & $2(11.1 \%)$ & 1.35 & 0.25 \\
\hline & Sitting and Standing & $38(76.0 \%)$ & $12(24.0 \%)$ & & \\
\hline \multirow[t]{2}{*}{ Frequent breaks } & Yes & $47(81.0 \%)$ & $11(19.0 \%)$ & 0.64 & 0.43 \\
\hline & No & $7(70.0 \%)$ & $3(30.0 \%)$ & & \\
\hline \multirow[t]{2}{*}{ Right posture } & Yes & $39(78.0 \%)$ & $11(22.0 \%)$ & 0.23 & 0.63 \\
\hline & No & $15(83.3 \%)$ & $3(16.7 \%)$ & & \\
\hline
\end{tabular}

Table 4. Duration of symptoms in relation to gender

\begin{tabular}{|c|c|c|c|c|c|}
\hline Sex & & $\begin{array}{l}\text { Working days lost due to } \\
\text { back pain }\end{array}$ & $\begin{array}{l}\text { No. of days of } \\
\text { back pain }\end{array}$ & $\begin{array}{l}\text { No. of days of } \\
\text { shoulder pain }\end{array}$ & $\begin{array}{l}\text { No. of days of } \\
\text { neck pain }\end{array}$ \\
\hline \multirow[t]{2}{*}{ Male } & Mean & 0.52 & 2.03 & 0.57 & 1.10 \\
\hline & SD & 1.39 & 1.54 & 0.87 & 1.35 \\
\hline \multirow[t]{2}{*}{ Female } & Mean & 0.81 & 2.17 & 0.89 & 0.86 \\
\hline & SD & 2.10 & 1.63 & 0.79 & 0.92 \\
\hline \multirow[t]{2}{*}{ Total } & Mean & 0.64 & 2.09 & 0.71 & 1.00 \\
\hline & SD & 1.73 & 1.57 & 0.84 & 1.18 \\
\hline
\end{tabular}

$\mathrm{SD}=$ Standard Deviation 


\section{REFERENCES}

1. Finsen L, Christensen H, Bakke M. Musculoskeletal disorders among dentists and variation in dental work. Appl Ergon 1998; 29(2):119-25.

2. Shugars D, Miller D, Williams D, Fishburne C, Srickland D. Musculoskeletal pain among general dentists. General Dentistry 1987;4:272-6.

3. Murtomaa H. Work related complaints of dentists and dental assistants. Int Arch Occup Environ Health 1982;50: 231-6.

4. Kajland A, Lindvall T, Nilsson T. Occupational medical aspects of the dental profession. Work Environ Health 1974;11:100-7.

5. Alexopoulos EC, Stathi IC, Charizani F. Prevalence of musculoskeletal disorders among dentists. BMC Musculoskelet Disord 2004;9(5):16.
6. Szymanska J. Disorders of the musculoskeletal system among dentists from the aspect of ergonomics and prophylaxis. Ann Agric Environ Med 2002;9:169-73.

7. Al Wazzan KA, Almas K, Al Shethri SE, Al-Qahtani MQ. Back and neck problems among dentists and dental auxillaries. J Contemp Dent Pract 2001;2(3):17-30.

8. Rundcrantz BL, Johnsson B, Moritz U. Pain and discomfort in the musculoskeletal system among dentists. A prospective study. Swed Dent J 1991;15(5):219-28.

9. Ratzon NZ, Yaros T, Mizlik A, Kanner T. Musculoskeletal symptoms among dentists in relation to work posture. Work 2002;15(3):153-8.

10. Marshall ED, Duncombe LM, Robinson RQ, Kilbreath SL. Musculoskeletal symptoms in New South Wales dentists. Aust dent J 1997; 42:240-6. 